\title{
A Review on the Book of A Study of Metonymy Through the Lens of Rhetorical Criticism
}

\author{
Yuhan Tian \\ Shandong University, Weihai, China \\ Tel: 178-6308-7170Ｅ-mail: tianyuhan@mail.sdu.edu.cn
}

Received: February 27, 2020, 2019 Accepted: March 22, 2020 Published: March 29, 2020

doi:10.5296/ijl.v12i2.16560

URL: https://doi.org/10.5296/ijl.v12i2.16560

\begin{abstract}
This paper reviews the book of A Study of Metonymy through the Lens of Rhetorical Criticism. In this book, the author, $\mathrm{Li} \mathrm{Ke}$, tries to analyze and evaluate metonymy through the lens of rhetorical criticism, and proposes a new research paradigm called critical metonymy analysis based on which metonymic competence is well constructed that can be applied to teaching practice. He finds that the research horizon of metonymy has been mainly confined to traditional linguistics in the past, hardly involving interdisciplinary research. Besides, domestic studies are inclined to merely introduce western research achievement, lacking original theories and research methods. Therefore, this book is of great value in both theoretical and practical aspects. Besides the advantages, this book can be refined by adding objects of critical metonymy analysis to extend its linguistic data. In addition, it can also be improved by classifying and analyzing these data systematically.
\end{abstract}

Keywords: Metonymy, Critical metonymy analysis, Rhetorical criticism, Rhetorical situation

\section{Introduction}

Studies on metonymy can be traced back to Aristotle in 330 B. C. Currently, metonymy has never lost vitality and has attracted a large number of scholars' attention. However, its research horizon is mainly confined to linguistic area, hardly involving interdisciplinary research. Recently, Li Ke, a Chinese scholar in Rhetorics and Cognitive Linguistics, has turned his 


\section{Ml Macrothink}

attention to the analysis and evaluation of metonymy under the frame of rhetorical criticism and attempted to construct a new research model with the combination of metonymy and rhetorical criticism, namely, critical metonymy analysis in A Study of Metonymy through the Lens of Rhetorical Criticism. In this work, Li elaborates metonymy as a subject for rhetorical criticism and clarifies the particular process of critical metonymy analysis innovatively, as well as the application to the foreign language teaching practice especially in reading, writing, and translation class. This paper will make a summary of the contents of this book, and then commend on the features of it briefly, as discussed below.

\section{The Summary of the Contents of the Book}

\subsection{The Introduction Part of the Book}

This book consists of nine parts. As an academic monograph, it begins in explaining the definitions of the main concepts in the title such as metonymy and rhetorical criticism in Chapter 1. Li also introduces research purposes, research significance, theoretical framework as well as research methods in this chapter.

As an ancient topic in the academic world, studies on metonymy can be traced back to Aristotle. But it has not received due focus until 1980s. In Chapter 2, Li reviews the previous researches on this topic in which metonymy was studied as either a kind of figure of speech or a kind of cognitive tool, domestically or abroad. He finds that there are problems in those researches, such as limited research horizon. And this book will analyze and evaluate metonymy based on rhetorical criticism theory, a novel perspective.

\subsection{Theoretical Construction}

As mentioned above, from Chapter 3 to Chapter 9, this book shows what critical metonymy analysis is and how it works in detail, as well as its application in language teaching practice.

In Chapter 3, Li starts with introducing the connotation of rhetorical criticism, including its definition, function, and classification. First, rhetorical criticism is defined as the systematic process of analyzing and evaluating research objects based on certain rhetorical theory of symbolic acts and systems in its broad sense and that of persuasive discourse and speech products (both spoken and written) in its narrow sense. Second, rhetorical criticism is used to interpret rhetorical artifacts on a deep level, thus enhancing people's capacity to view it comprehensively. Third, four rhetorical criticism models are concluded, which are Neo-Aristotelian, sociological perspective, dramaturgical perspective, and postmodern criticism. (Wen, 2006; Cong \& Xu, 2007; Foss, 2004; Hart \& Susanne, 2005; Kuypers, 2005; Burgchardt, 2005) And these models can be classified into two stages in terms of the time of generation: the traditional rhetorical criticism stage and the new rhetorical criticism stage. At the end of this Chapter, the denotation of rhetorical criticism is expounded, which is the concrete analytical 


\section{Ml Macrothink}

procedure. Li claims that three steps are supposed to be taken in turn in rhetorical criticism procedure, which are description, describing the relative characteristics of the rhetorical artifact, interpretation, revealing the motivation, value, and ideology behind it by analyzing the relationship between its characteristics and involved factors such as context, and evaluation, evaluating the conclusion of last two steps according to certain criteria.

Metonymy, in this research, is redefined based on the integration of perspectives of figure of speech and cognitive tool in Chapter 4. In addition, the function and steps of rhetorical criticism for metonymy are also redefined under the framework of rhetorical criticism. Critical metaphor analysis is closely interconnected with rhetorical criticism both in the theory's nature and analytical method, which provides references for critical metonymy analysis as metonymy is also interrelated with metaphor. Li expounds the two keywords--"criticism" and "metonymy" in detail. The former combines the conception of criticism in critical discourse analysis and that in rhetorical criticism. The latter is redefined based on the integration of perspectives of figure of speech and cognitive tool. The book also clarifies the objects, functions, and analytical procedures of critical metonymy analysis. In the end, Li concluded that critical metonymy analysis needs to be supported by rhetorical theory and it also enriches rhetoric in turn.

From Chapter 5 to Chapter 7, Li illuminates the procedures of description, interpretation, and evaluation respectively. In Chapter 5, he makes it clear what the description of metonymy is. Metonymy is described in terms of both metonymy recognition and terministic screen. Metonymy recognition takes contiguity, ICM, the part-whole and part-part interrelationships, and context as identification parameters. Terministic screen is defined as symbol system and sets of words people use, which select, reflect, and deflect the reality (Liu 2008). Its selective reflection of and deviation from reality can reveal the salience of metonymy.

In Chapter 6, Li moves to clarify the process of metonymy interpretation. It means to reveal the speaker or writer's rhetorical motive and the discourse's ideological meaning by analyzing the relationship between metonymy and its social and cultural context. Thus rhetorical situation, rhetorical motive, and ideology are three keywords involved in the interpretation of metonymy. The book introduces rhetorical situation through the analysis of Bitzer's (1968) definition of rhetorical situation, Vatz (1973)'s rhetorical situation, and Burke's (1973) rhetorical situation. Li asserts that rhetorical situation should be mastered in both broad and narrow sense. Besides, he finds that different rhetorical situations can not only influence and restrain metonymy but also be reshaped by it. Then the book moves to describe rhetorical motive. The author explains that rhetorical motive is not supposed to be limited to situational level because it is actually a kind of motive to act with strong intentionality. As a linguistic phenomenon, metonymy is also concerned with rhetorical motive which deserves a systematic analysis and evaluation. And the systematic analysis and evaluation shall work by different factors and levels. As for ideology, the author reveals the ideological meaning of metonymy through analyzing it as linguistic 


\section{Mll Macrothink}

phenomena. It is concluded that the ideological view in critical metonymy analysis can be classified into two versions: a weak one and a strong one. The strong one aims to reveal the inequality involved in power and politics which is concerned with political transformation and political system. While the weak one refers to the perspective, attitude, and values people maintain to view and understand the world.

When it comes to the procedure of evaluation in Chapter 7, Li believes that the discourse criterion is supposed to be considered as one of the criteria for metonymy evaluation together with truth criterion, ethical criterion, and artistic criterion based on Campbell \& Burkholder (1997)'s theory. And the ultimate goal, is to reveal the rhetor's intention to persuade the audience and achieve identification with audience by critical metonymy analysis. The author demonstrates it by giving examples of critical metonymy analysis in political text, sports news text, and advertisement text. He ends up this Chapter with an instance analysis including all the three procedures of critical metonymy analysis.

\subsection{The Application of the Critical Metonymy Analysis}

Besides the theoretical construction, this book is also concerned with the application of critical metonymy analysis into English language teaching including reading, writing, and translation. In Chapter 8, Li clarifies what metonymic competence is, based on the research paradigms of critical metonymy analysis. Then he discussed how important the role of metonymic competence plays in the teaching of English reading, writing, and translation is. Learning from metaphoric competence, the author makes a conclusion that metonymic competence is concerned with the following five abilities: the ability to describe metonymy, to explain metonymy quickly, to evaluate metonymic selection, and to create and apply metonymy in language practice, and to understand the world in terms of the relationship between macro and micro levels. All these five abilities have certain directive significance in the teaching of English reading, writing, and translation. First, Li takes the teaching of "Advanced English" as an example to demonstrate that metonymic competence plays a significant role in both teaching and learning of English reading. It can arouse students' interest in reading, help them view language from a new perspective, and understand the text comprehensively, thus improving teaching effect. Second, English writing, as a form of language production, is influenced by many vital factors, one of which is metonymic competence. The usage of metonymy can add artistry into the text to some degree. And the author demonstrates that all the five abilities of metonymic competence are reflected in metonymy's production by giving a typical example. Li believes teachers should gradually pay attention to training students' ability to create proper metonymy in their writing and view the world in both micro and macro. As for translation, metonymic competence is also critical. Li advise teachers to guide students to evaluate that translation version at the macro level. 


\section{Macrothink}

In Chapter 9, Li concludes this book with its core argument that the three steps that the study of metonymy from the perspective of rhetorical criticism (critical metonymy analysis) takes can make systematic analysis and evaluation for metonymy. Besides, it has great enlightening significance about practice in English teaching of reading, writing, and translation depending on the metonymic competence structured by critical metonymy analysis. The author also summarizes the shortcomings of this book and outlook on the further research. He suggests that multi-disciplinary integration of rhetoric with other disciplines should attract more attention in the further investigations of rhetoric.

\section{Comments on the Book}

\subsection{The Strengths of This Book}

As mentioned in the first paragraph, this book is one of the few books that specialized in the study of metonymy under the frame of rhetorical criticism. It is valuable both theoretically and practically.

\subsubsection{The Theoretical Value}

In general, compared with the similar books on this topic, this book has considerable merits in three respects: First, it clearly defines metonymy as an object of rhetoric criticism. Although metonymy, as an ancient research field, is studied deeply in terms of figure of speech and cognitive linguistics respectively, there is no such a definition that takes both items into consideration. In this book, the author presents studies on metonymy from the perspective of both a kind of figure of speech and a kind of cognitive tool, domestically or abroad, giving a reasonable definition. And by doing this, the essential features of metonymy are clearly illuminated.

Second, this book clarifies what rhetorical criticism is, including its connotation and denotation. Although rhetorical criticism has been a large-scale study field abroad with many influential monographs for almost a century, not much attention has been paid to it until recent ten years domestically. There is a development lag. In addition, definitions that have been given about rhetorical criticism are so heterogeneous that it is difficult to figure out which one is scientific considering the researcher's angle or historical factors. In this book, the author redefines rhetorical criticism by distinguishing it from the broad and narrow sense. He also clarifies its function and model, together with concrete analysis steps.

Third, a theoretical framework of critical metonymy analysis is constructed. This is one of the most innovative points in the research. Enlightened by critical metaphor analysis, critical metonymy analysis is defined as a systematic analysis and evaluation of metonymy phenomenon in discourse based on rhetorical criticism theory in a narrow sense. Li refers that the objects of critical metonymy analysis include some certain types of discourse, mainly political oration 


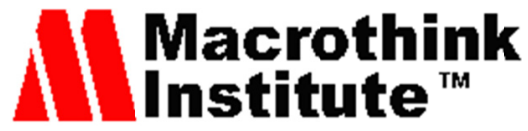

discourse, sports news discourse, advertisement discourse, and part of literary discourse. As for functions, four aspects are clarified, that is, revealing termnistic screen, indicating rhetorical motive and ideological meaning, improving the audiences' critical awareness, and finally, training the audience's metonymic competence. When it comes to procedures of critical metonymy analysis, three steps are taken in turn---- description of metonymy, interpretation of metonymy, and evaluation of metonymy. This book breaks through the stalemate in which the studies on metonymy are limited in the linguistic field and tries to study metonymy in terms of western rhetoric, which can be seen as an inter-disciplinary research.

Fourth, the analysis steps of critical metonymy analysis are expounded based on rhetoric. Termnistic screen, rhetorical situation, rhetorical motive and so on are regarded as the firm theoretical basis for critical metonymy analysis, which run through all the three analysis steps. Specifically speaking, description of metonymy includes metonymy recognition and terministic screen analysis. Interpretation of metonymy refers to analyzing the result of last step to reveal rhetorical motive and ideological meaning. Evaluation of metonymy means evaluating metonymy systematically based on certain standards by analyzing the results concluded in the last two procedures to reveal the rhetor's intention to persuade the audience and achieve identification.

\subsubsection{The Practical Value}

In addition, this book defines metonymic competence reasonably under the framework of critical metonymy analysis, which is instructive in the teaching practice of English reading, writing, and translation. It includes the following five aspects: the ability to describe metonymy to explain metonymy, to evaluate metonymic selection, to create and apply metonymy in language practice, and to understand the world in terms of the relationship between macro and micro levels. These five aspects are concrete and comprehensive, which are important innovative points considering practical value. According to the research, metonymic competence plays a significant role in English teaching, which can effectively arouse students' interests, thus is beneficial for both learning and teachings.

\subsection{The Shortcomings of This Book}

Although this book has made significant breakthroughs, there are still some shortcomings: First, since political discourse, sports news discourse, advertisement discourse, and part of literary discourse are regarded as the main objects of critical metonymy analysis, the linguistic data chosen in the research are limited. Actually, metonymy also exists in other discourses such as entertainment news text, which also deserves analyzing deeply. But this book does not mention it as a result of limited space. 


\section{$\Lambda$ Macrothink}

Second, as far as the organization of linguistic data is concerned, this book does not classify and analyze them systematically, only demonstrating some of them according to the intensity sampling principle. This strategy of scattered organization for linguistic data may have negative influences on the overall effect of argument.

Third, some conceptions mentioned need to be weighed and demonstrated. For example, this book distinguishes rhetorical criticism in a broad sense from that in a narrow sense. Rhetorical situations are also distinguished in such way. However, "broad" and "narrow" is a couple of relative conceptions, which cannot be differentiated by objective criteria. So the classification itself is subjective and limited to some extent.

Finally, when it comes to the practical value of metonymic competence, this book only refers to its enlightening significance in teaching for reading, writing, and translation. However, it also works in the teaching for listening and speaking, though maybe in non-intuitive ways, which needs to be dug out. The defects cannot obscure the virtues. Though it is imperfect, this book is of great value in bridging western rhetoric, traditional rhetoric, and cognitive linguistics.

\section{References}

Burgchardt, C. R. (2005). Readings in rhetorical criticism. State College, Penn: Strata Publishing, Inc.

Campbell, K. K., \& Thomas, R. B. (1997). Critiques of contemporary rhetoric (2nd ed.). Belmont: Wadsworth.

Cong, L. T., \& Xu, L. Y. (2007). Western rhetoric. Shanghai: Shanghai Foreign Language Education Press.

Foss, S. K. (2004). Rhetorical criticism: Exploration \& Practice. Long Grove: Waveland Press.

Hart, R. P., \& Susanne, M. D. (2005). Modern rhetorical criticism. Boston: Pearson/Allyn \& Bacon.

Kenneth, B. (1973). The rhetorical situation. In L. Thayer (Ed.), Communication: Ethical and Moral Issues (pp. 263-275). New York: Gorden and Breach Science Publishers.

Kuypers, J. A. (2005). The art of rhetorical criticism. Boston: Pearson Education.

Liu, Y. M. (2008). History of western rhetoric. Beijing: Foreign Language Teaching and Research Press.

Lloyd, B. (1968). The rhetorical situation. Philosophy and Rhetoric, 1, 1-14.

Vatz, R. (1973). The myth of the rhetorical situation. Philosophy and Rhetoric, 6(3), 154-160. 
Wen, K. X. (2006). A theoretical study of western rhetoric in the 20th century. Beijing: China Social Sciences Press.

\section{Copyrights}

Copyright for this article is retained by the author(s), with first publication rights granted to the journal.

This is an open-access article distributed under the terms and conditions of the Creative Commons Attribution license (http://creativecommons.org/licenses/by/4.0/) 